\title{
Age Wise Histological Studies on the Major Lymphoid Organs in Various Chicken Genotypes
}

\author{
N. Dahariya ${ }^{1}$, S. Sathapathy ${ }^{1}$, R. Patra ${ }^{1}$, U.K. Mishra ${ }^{1}$, S.K. Sahu ${ }^{1}$, L. Samal ${ }^{2}$, Biswadeep Jena ${ }^{3}$ and S.K. Joshi $^{4}$ \\ ${ }^{1}$ Department of Veterinary Anatomy and Histology, CVSc. and A.H., OUAT, Bhubaneswar, Odisha, INDIA \\ ${ }^{2}$ AICRP on Poultry Breeding, CVSc. and A.H., OUAT, Bhubaneswar, Odisha, INDIA \\ ${ }^{3}$ Department of Veterinary Surgery and Radiology, CVSc. and A.H., OUAT, Bhubaneswar - 751 003, Odisha, INDIA \\ ${ }^{4}$ Scientist (Animal Science), KVK, Jharsuguda, OUAT, Bhubaneswar, Odisha, INDIA \\ "Corresponding author: S Sathapathy; E-mail: srinivas.sathapathy@gmail.com
}

Received: 13 Sept., 2020

Revised: 10 Oct., 2020

Accepted: 17 Oct., 2020

\begin{abstract}
A total number of eighteen day old Hansli chicks and eighteen day old Vencobb broiler chicks were divided into three age groups viz. group I (up to 1 month), group II (1-3 months) and group III (3-6 months) with six birds in each age group. It was revealed that the thymus was surrounded by a capsule and comprised of peripheral darker cortex and central lighter medulla. There was presence of lymphocytes, reticular cells, plasma cells, macrophages, fibroblasts, dendritic cells and erythrocytes in both the cortex and medulla of thymus in both the birds in all the age groups. The spleen was surrounded by a dense irregular connective tissue capsule. The splenic white pulp had lymphocytes of various sizes, dendritic cells, macrophages and blood vessels. The splenic red pulp consisted of splenic cords and venous sinuses. The splenic cords had erythrocytes, reticular cells, lymphocytes of various sizes, heterophils and plasma cells. The wall of the bursa consisted of innermost tunica mucosa, middle tunica muscularis and outermost tunica serosa. The follicle-associated epithelium of the plicae was pseudostratified ciliated columnar type with areas of simple cuboidal cells. There was presence of lymphocytes of various sizes, reticular cells, plasma cells, macrophages, dendritic cells and fibroblasts in both the cortex and medulla of bursal follicles. The collagen, reticular and elastic fibres were reported in different regions of thymus, spleen and bursa of Fabricius in both the birds.
\end{abstract}

\section{HIGHLIGHTS}

(0 The thymus and bursa regressed at $24^{\text {th }}$ week of age in Hansli and Vencobb broiler chicken.

(0 The follicular pattern were absent in the plicae of bursa.

Keywords: Age, Bursa of Fabricius, Hansli, histology, spleen, thymus, Vencobb

The organized poultry sector contributes about 70 per cent of the total output of poultry industry and the remaining 30 per cent is shared by the unorganized sector (Ali, 2015). The indigenous breeds of chickens mostly contribute to the rural economies in most of the underdeveloped and developing countries like India (Dahariya et al., 2020a). The environment rural relations and demand of food safety in recent years might encourage the use of native fowl in a gastronomical niche market (Ekka et al., 2016). Besides, providing nutritious chicken egg and meat for consumption, the native fowl play an incredible role in giving the subsidiary income to the rural poor and marginalized section of the people in our country (Padhi, 2016). The Hansli chicken is especially reared in Mayurbhanj district and in some parts of its nearby districts like Keonjhar of Odisha (Mohapatra et al., 2016). The Hansli chicken is very well adapted to the hot and humid tropical climates of Odisha and has been mainly

How to cite this article: Dahariya, N., Sathapathy, S., Patra, R., Mishra, U.K., Sahu, S.K., Samal, L., Jena, B. and Joshi, S.K. (2020). Age wise histological studies on the major lymphoid organs in various chicken genotypes. J. Anim. Res., 10(5): 811-819.

Source of Support: None; Conflict of Interest: None (c) 9 
reared for meat, egg and game purpose (Dahariya et al., 2020b).

The basic structures of the lymphoid organs pave the way to understand their physiology and their age. The basic structures of the lymphoid organs pave the way to understand their physiology and their role in providing immunity. Several works have been reported on the lymphoid system of broiler chicken (Khan et al., 2014), domestic chicken (Kannan et al., 2015), Japanese quail (Senapati et al., 2015) and turkey (Ali, 2016) has been done, but very scarce literature is available on the lymphoid system of Hansli chicken and Vencobb broiler chicken till date. Viewing the increased popularity of the Hansli chicken and Vencobb broiler chicken in Odisha, the present study is carried out on the histological development of major lymphoid organs in these breeds with age.

\section{MATERIALS AND METHODS}

A total number of eighteen day old Hansli chicks and eighteen day old Vencobb broiler chicks were purchased from Mayurbhanj district and Eastern Hatcheries Pvt. Ltd., Bhubaneswar, Odisha (A subsidiary of Venkateswara Hatcheries Group, Pune) respectively to study the posthatched development of major lymphoid organs such as thymus, spleen and bursa of Fabricius. The birds (Hansli chicken and Vencobb broiler chicken) were divided into three age groups viz. group I (up to 1 month), group II (1-3 months) and group III (3-6 months) with six birds in each age group. On each observation day $\left(4^{\text {th }}\right.$ week, $12^{\text {th }}$ week and $24^{\text {th }}$ week), six birds from each breed were used for the study of histological features of the thymus, spleen and bursa of Fabricius. The representative tissue samples were collected after careful dissection of the organs. They were then processed by routine paraffin technique (Bancroft and Stevens, 1996) and were stained by Haematoxylin and Eosin (Bancroft and Stevens, 1996), Masson's trichrome stain for the presence of collagen fibers (Bancroft and Stevens, 1996), Verhoeff's stain for the presence of elastic fibers (Bancroft and Stevens, 1996) and Gomori's stain for the presence of reticular fibers (Bancroft and Stevens, 1996).

\section{RESULTS AND DISCUSSION}

Thymus

The thymus was covered by a dense irregular connective tissue capsule in all the age groups of both Hansli chicken and Vencobb broiler chicken. The connective tissue septa or trabeculae araised from the thymic capsule and extended into each thymic lobe (Fig. 1).

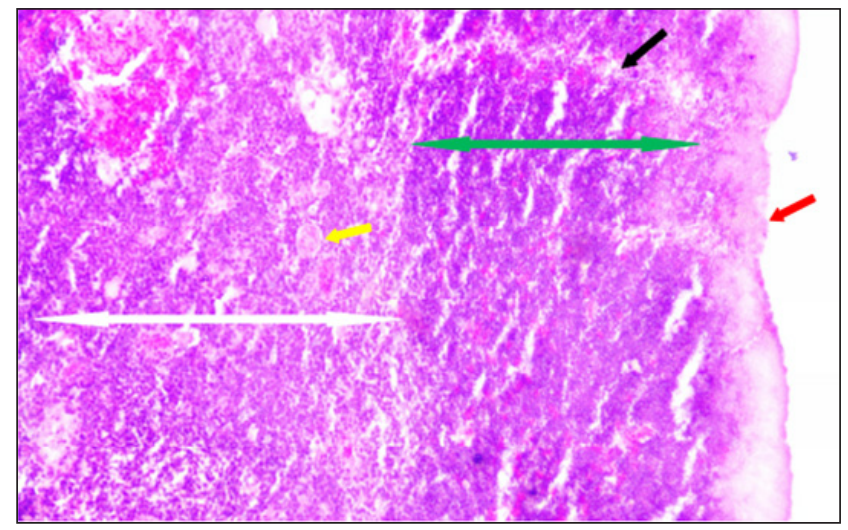

Fig. 1: Photomicrograph showing capsule (red arrow), cortex (green arrow), medulla (white arrow), trabeculae (black arrow) and Hassall's corpuscle (yellow arrow) in the thymus of Hansli chicken $\left(4^{\text {th }}\right.$ week $)(H \& E \times 100)$

The trabeculae divided the lobes into lobules. The present observations were in accordance with the reports given by Singh et al. (2010) and Lochi et al. (2014) in chicken, Gulmez and Aslan (1999) in native geese, Sultana et al. (2011) in ducklings of Bangladesh and Mahanta (2018) in local hill fowl of Uttarakhand and RIR. The lobulation pattern of the thymus was comparatively more distinct with much wider trabeculae in the thymus of $4^{\text {th }}$ week age Vencobb broiler chicken than Hansli chicken of the same age group. In some cases, the trabeculae even extended deep into the medulla coursing the whole thickness of the thymus in $4^{\text {th }}$ week age Vencobb broiler chicken. Most of the trabeculae resembled like crypts in $4^{\text {th }}$ week age Vencobb broiler chicken. The amount of blood vessels was also comparatively more in number in both cortex and medulla of the thymus of $4^{\text {th }}$ week age Vencobb broiler chicken than Hansli chicken of the same age group. The cortex was stained much darker in $12^{\text {th }}$ week age Hansli chicken and it was comprised of numerous small lobules as compared to the cortex of $4^{\text {th }}$ week age Hansli chicken. Most of the trabeculae extended deep into the medulla in $12^{\text {th }}$ week age Hansli chicken. Some of the trebeculae travelled obliquely and anastomosed with the adjacent trabeculae forming cross connections in $12^{\text {th }}$ week age Hansli chicken. Further, the amount of blood vessels was 
also comparatively more in number in both cortex and medulla of the thymus of $12^{\text {th }}$ week age Hansli chicken than $4^{\text {th }}$ week age Hansli chicken.

The collagen (Fig. 2) reticular (Fig. 3) and elastic fibers were reported in the thymic capsule, septa or trabeculae and tunics of capsular and trabecular blood vessels of both Hansli chicken and Vencobb broiler chicken in all the age groups. The splenic parenchyma had reticular fibers. The amount of collagen and reticular fibers in capsule and septa increased with age in both the Hansli chicken and Vencobb broiler chicken.

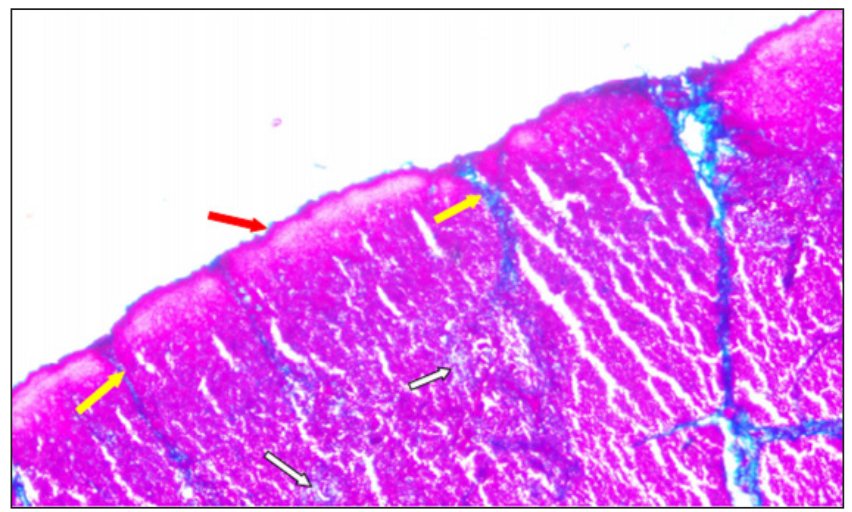

Fig. 2: Photograph showing collagen fiber in capsule (red arrow), trabeculae (yellow arrows) and Hassall's corpuscle (white arrows) in thymus of Hansli chicken (12 ${ }^{\text {th }}$ week) (Masson's trichrome $\mathrm{x} 400$ )

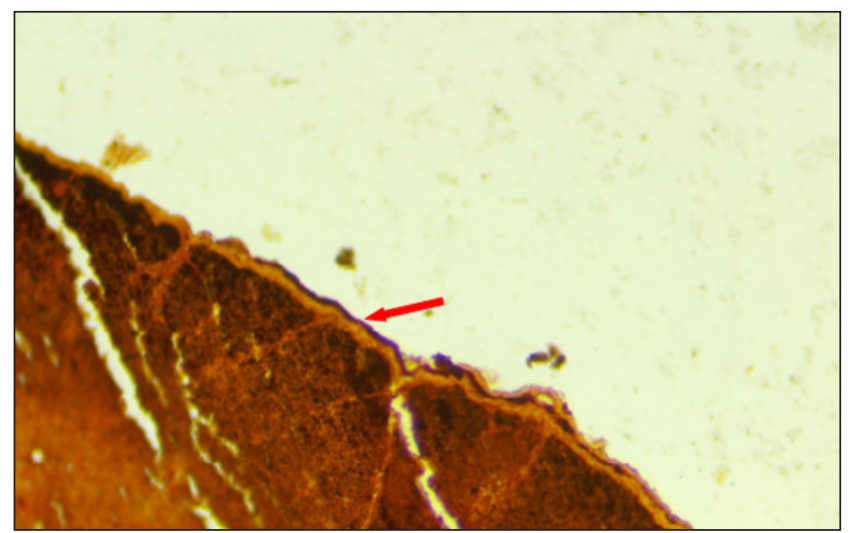

Fig. 3: Photograph showing reticular fiber in thymic capsule (red arrow) of Hansli chicken (12 ${ }^{\text {th }}$ week) (Gomori's method $\left.x 400\right)$

However, the amount of elastic fibers in the thymic capsule and septa decreased in $24^{\text {th }}$ week age. The amount of reticular fibers increased with age at $24^{\text {th }}$ week of age that subsequently replaced the lymphocytes and reticuloepithelial cells which marked the process of regression of the organ in both the birds at this age. The present observations were in accordance with the reports given by Mahanta (2018) in local hill fowl of Uttarakhand and RIR.

Each thymic lobe was distinctly divided into peripheral darkly stained cortex and central lightly stained medulla in both Hansli chicken and Vencobb broiler chicken in all the age groups. The cortex of thymic lobe comprised of densely packed lymphocytes of different size in the network of reticuloepithelial cells in both Hansli chicken and Vencobb broiler chicken in all the age groups. Hence, it was stained dark. The medulla of thymic lobe comprised of loosely packed lymphocytes of different size in the network of reticuloepithelial cells in both Hansli chicken and Vencobb broiler chicken in all the age groups. Hence, it was stained light. The thymic lobes had numerous small lobules with darkly stained cortex in $12^{\text {th }}$ week age Vencobb broiler chicken. Angiogenesis was quite evident in this age in Vencobb broiler chicken. The cortex was stained comparatively lighter in $24^{\text {th }}$ week age Hansli chicken as compared with the cortex of $12^{\text {th }}$ week age Hansli chicken. Further, the medulla was populated with connective tissue elements in $24^{\text {th }}$ week age, which indicated the process of regression of the organ in Hansli chicken at this age.

There was presence of collagen, reticular and elastic fibers in the medulla of the thymus in both Hansli chicken and Vencobb broiler chicken. The amount of the connective tissue fibers increased with age in both the birds and replaced the lymphocytes during involution. The present observations were in accordance with the reports given by Singh et al. (2010) in chicken, Sultana et al. (2011) in ducklings of Bangladesh, Song et al. (2012) in Ostrich chicks, Lochi et al. (2014) in Aseel chicken and Mahanta (2018) in local hill fowl of Uttarakhand and RIR. The reticuloepithelial cells appeared as large vesicular cells in both cortex and medulla of each thymic lobe in both Hansli chicken and Vencobb broiler chicken. There was presence of small, medium and large sized lymphocytes in both cortex and medulla of each thymic lobe in both Hansli chicken and Vencobb broiler chicken. The reticuloepithelial cells along with lymphocytes were arranged concentrically to form thymic corpuscle or Hassall's corpuscle in the cortex, cortico-medullary junction and medulla of each thymic lobe in both Hansli 
chicken and Vencobb broiler chicken (Fig. 4). There was also presence of erythrocytes, heterophils, plasma cells and fibroblasts in the Hassall's corpuscle. The fibroblasts were spindle shaped cells having central round nucleus and often found in the capsule and trabeculae. The neuroendocrine cells were oval shaped with centrally located light stained nucleus surrounded by darkly stained cytoplasm located in the medulla of the thymus.

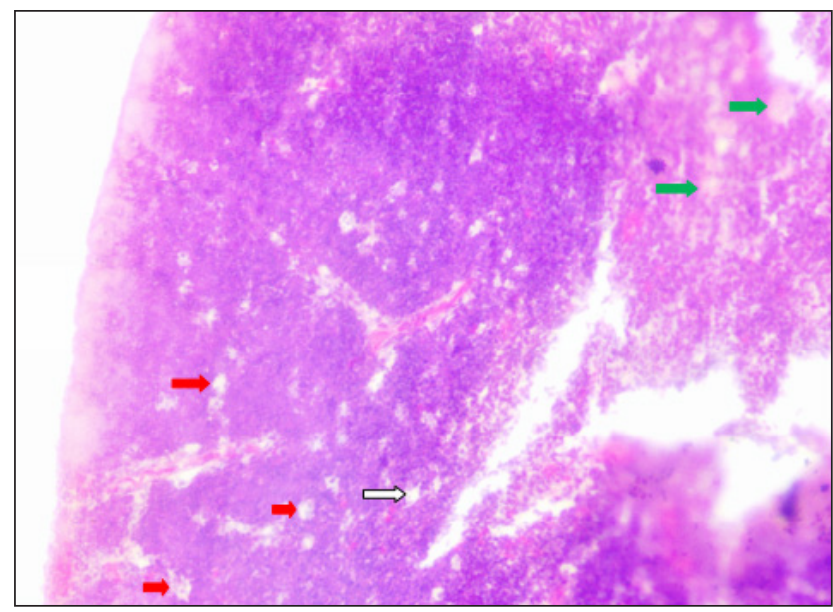

Fig. 4: Photograph showing Hassall's corpuscle in the cortex (red arrows), cortico-medullary junction (white arrow) and medulla (green arrows) of thymus of Vencobb broiler chicken $\left(4^{\text {th }}\right.$ week $)(H \& E \times 1000)$

\section{Spleen}

The splenic parenchyma was surrounded by a thin fibrous dense irregular connective tissue capsule in both the Hansli chicken and Vencobb broiler chicken in all the age groups. Few amount of smooth muscle fibers were also reported in the capsule of the organ. The splenic capsule mainly comprised of collagen fibers (Fig. 5) with very few amount of reticular and elastic fibers in both Hansli chicken and Vencobb broiler chicken. The splenic capsule and sub-capsular area had very few amount of elastic fibers in both Hansli chicken and Vencobb broiler chicken in all the age groups. Further, these connective tissue fibers increased in the spleen with age in both the birds and they imparted elasticity to the organ. Numerous trabeculae or septa araised from the splenic capsule and invaded the substance of splenic parenchyma. The present observations were in agreement with the findings of Venkatesan and Vijayaragavan (1999) in Japanese quail, Akter et al.
(2006) in broiler chicken and Mahanta (2018) in local hill fowl of Uttarakhand and RIR. These septa formed passage for the trabecular arteries and trabecular veins. Lymphocytes of various sizes, reticular cells, plasma cells, dendritic cells, fibroblasts, macrophages, erythrocytes and other leukocytes were reported in the splenic parenchyma in both Hansli chicken and Vencobb broiler chicken in all age groups. The present observations were in agreement with the findings of Venkatesan and Vijayaragavan (1999) in Japanese quail, Akter et al. (2006) in broiler chicken, Sultana et al. (2011) in duckling of Bangladesh, Kannan and Ramesh (2013) in Nandanam chicken and Mahanta (2018) in local hill fowl of Uttarakhand and RIR.

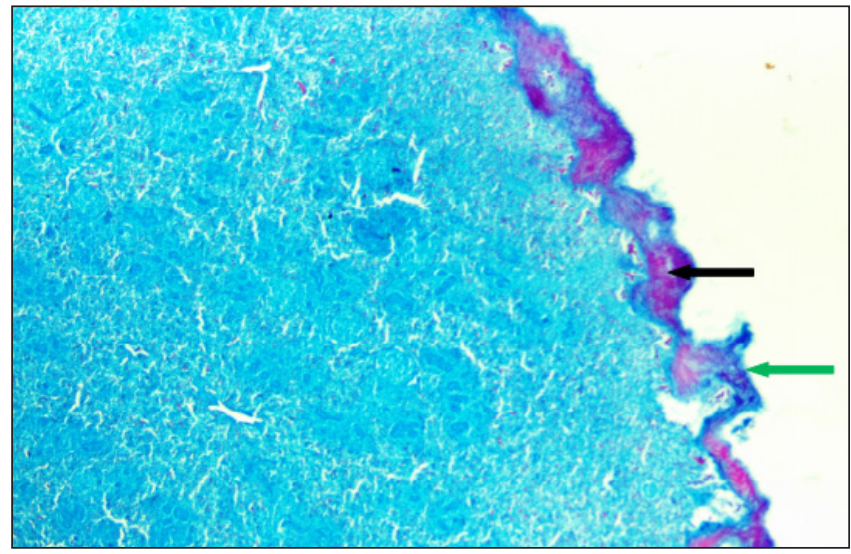

Fig. 5: Photograph showing collagen fiber (green arrow) and smooth muscle fiber (black arrow) in the capsule of spleen of Hansli chicken (12 ${ }^{\text {th }}$ week) (Masson's trichrome $\left.\mathrm{x} 400\right)$

The splenic parenchyma was comprised of round to oval lightly stained regularly organized white pulp and darkly stained irregularly arranged red pulp in all the age groups in both Hansli chicken and Vencobb broiler chicken (Fig. 6). The splenic white pulp consisted of central artery and arterioles surrounded by densely packed mass of lymphocytes of various sizes forming the peri arterial lymphatic sheath (PALS) in all the age groups of birds. The white pulp was present in diffused form among the red pulp in $4^{\text {th }}$ and $12^{\text {th }}$ week age Vencobb broiler chicken, whereas the splenic white pulp was reported in discrete patches among the red pulp in Hansli chicken at same age groups.

The collagen, reticular and few amounts of elastic fibers were noted in the tunics of the central artery and arterioles of the splenic white pulp. There was presence of very few 
lymphatic nodules or splenic nodules in the white pulp of deeper part of spleen in $4^{\text {th }}$ week age Hansli chicken, whereas these were present in the white pulp areas of subcapsular region and deeper part of spleen in $4^{\text {th }}$ week age Vencobb broiler chicken.

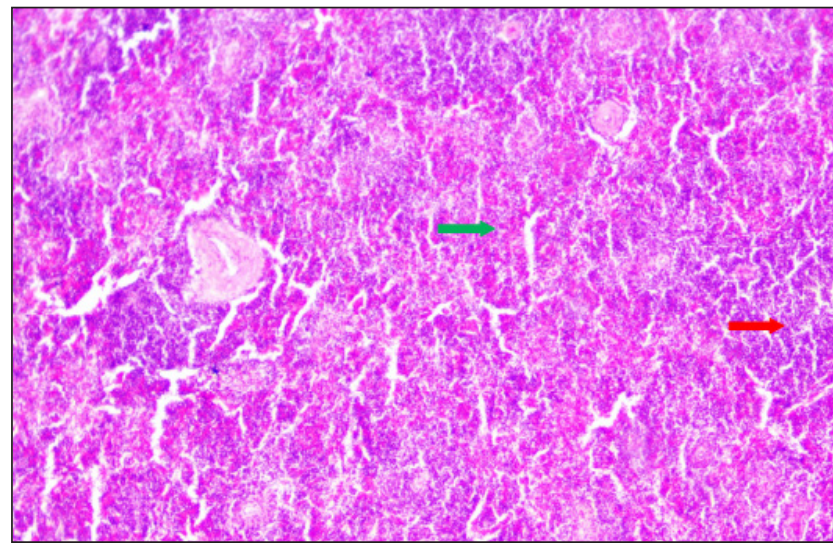

Fig. 6: Photograph showing white pulp (red arrow) and red pulp (green arrow) in the splenic parenchyma of Hansli chicken $\left(24^{\text {th }}\right.$ week) (H\&E x100)

Further, their number increased in $12^{\text {th }}$ week of age in both the birds. The splenic nodules were reported in the white pulp areas of subcapsular region and deeper part of the spleen in $12^{\text {th }}$ week age of both the birds. Very few splenic nodules were reported in the white pulp of deeper part of spleen in $24^{\text {th }}$ week age of Hansli chicken. The splenic nodules had lymphocytes of various sizes and categorized into small, medium and large lymphocytes. Some of the lymphatic nodules contained lightly stained central area surrounded by darkly stained area. This lightly stained area was referred as germinal centre. There was presence of a dark basophilic zone known as marginal zone in between the splenic red pulp and white pulp. This zone had lymphocytes of various sizes, reticular cells and macrophages. Further, venous sinuses known as marginal sinus were reported at the periphery of marginal zone. The present observations were in agreement with the findings of Mahanta (2018) in local hill fowl of Uttarakhand and RIR.

The splenic red pulp consisted of splenic cords and venous sinuses or venules. The splenic cords had reticular fibers, reticular cells, macrophages, erythrocytes, lymphocytes, plasma cells and other leukocytes. The arterioles those entered the splenic red pulp from the white pulp were divided into capillaries and these were surrounded by the lymphocytes of various sizes, reticular cells and macrophages known as sheathed or ellipsoid capillaries. This lymphoid sheath was referred as peri-ellipsoidal lymphatic sheath (PELS). The capillaries had narrow lumen and their endothelium was cuboidal type with centrally located nucleus surrounded by lightly stained pinkish cytoplasm (Fig. 7). Fine networks of reticular fibers and elastic fibers were also recorded in the PELS areas of spleen in both the birds.

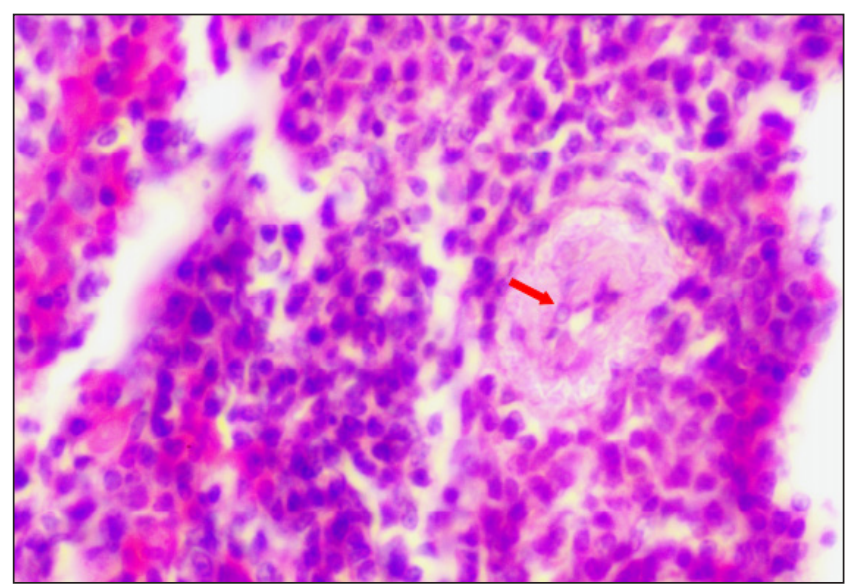

Fig. 7: Photograph showing cuboidal cells of splenic capillary in Hansli chicken $\left(24^{\text {th }}\right.$ week) (H\&E x1000)

\section{Bursa of Fabricius}

The wall of the bursa of Fabricius had innermost tunica mucosa, middle tunica muscularis and outermost tunica serosa in both Hansli chicken and Vencobb broiler chicken in all the age groups (Fig. 8).

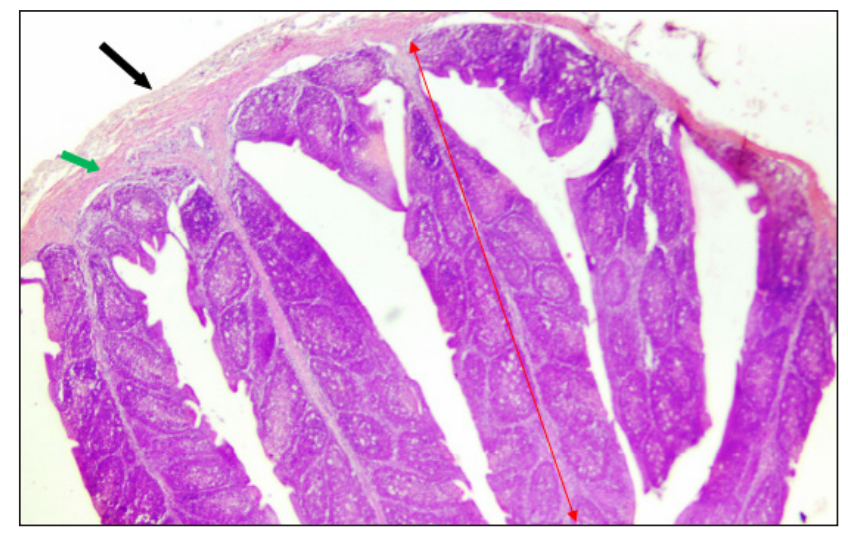

Fig. 8: Photograph showing tunica mucosa (red arrow), tunica muscularis (green arrow) and tunica serosa (black arrow) of bursa of Fabricius of Vencobb broiler chicken ( $4^{\text {th }}$ week) (H\&E $\mathrm{x} 100)$ 
The present finding was in accordance with the reports of Gulmez and Aslan (1999) in native geese, Indu et al. (2005) in White Pekin ducks, Singh et al. (2010) in chicken, Hassan et al. (2011) in quail and Mahanta (2018) in local hill fowl of Uttarakhand and RIR. But it was contradicting to the finding of Song et al. (2012) who observed that the bursa was comprised of a mucosa, a submucosa, a muscular layer and an adventitia in ostrich chicks.

The Tunica mucosa of the bursa was arranged into so many longitudinal folds known as plicae. They were categorized into smaller and larger plical folds. Each bursal plica comprised of surface epithelium and lamina propria. The lamina propria was filled with numerous lymphoid follicles. There was presence of connective tissue core inside each bursal plicae that originated from the base of plicae and ran up to their apices. The connective tissue trabeculae or septa originated from this connective tissue core and ran into the substance of each bursal plicae dividing them into different compartments. The central connective tissue core of each bursal plica was comprised of numerous collagen fibers (Fig. 9), reticular fibers (Fig. $10)$ and very few elastic fibers as reported by Indu et al. (2005) in White Pekin ducks, Jayachitra et al. (2009) in turkeys, Singh et al. (2010) in chicken and Mahanta (2018) in local hill fowl of Uttarakhand and RIR. There was presence of large blood vessels in the connective tissue core of the bursal plica.

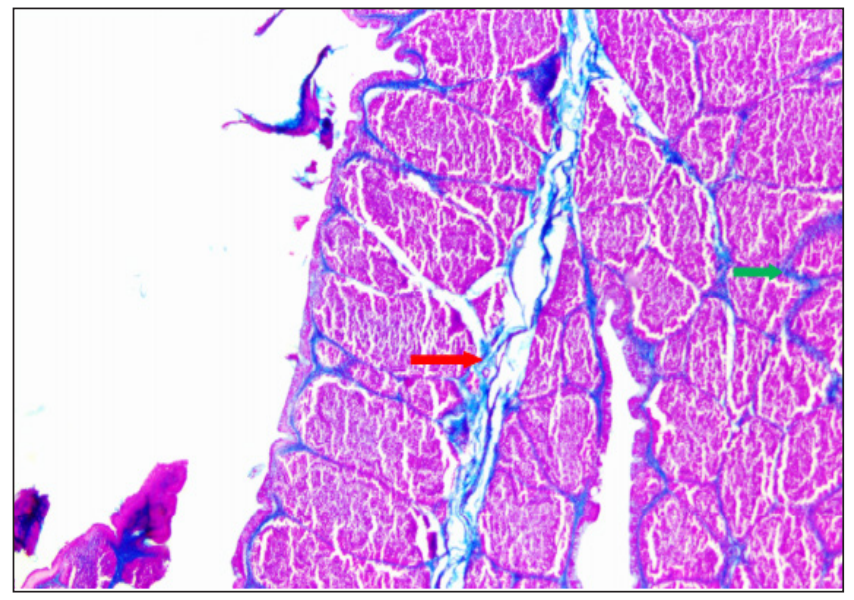

Fig. 9: Photograph showing collagen fiber in the central plical connective tissue core (red arrow) and between lymphoid follicles (green arrow) in the bursa of Fabricius of Hansli chicken ( $4^{\text {th }}$ week) (Masson's trichrome $\mathrm{x} 400$ )

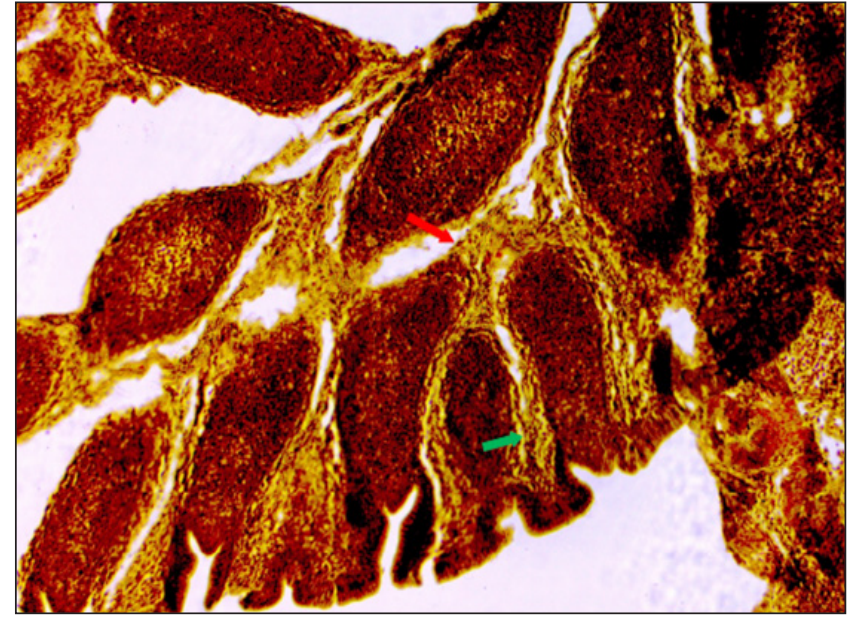

Fig. 10: Photograph showing reticular fiber in the central connective tissue core of plicae (red arrow) and between lymphoid follicles (green arrow) of bursa of Fabricius in Hansli chicken $\left(4^{\text {th }}\right.$ week) (Gomori's method x100)

The surface of the bursal plica was wavy in outline and consisted of raised and depressed pitted area. The pitted areas of tunica mucosa were mostly lined by pseudostratified ciliated columnar cells with numerous goblet cells. Further, the surface epithelium of bursa was categorized into Follicle-Associated Epithelium (FAE) and Inter Follicular Epithelium (IFE). The interfollicular epithelium (IFE) shared a small portion of the surface epithelium of the bursa in both Hansli chicken and Vencobb broiler chicken. The present report was contradicting to the findings of Jayachitra et al. (2009) in turkeys who observed that the interfollicular epithelium shared the bulk of the surface epithelium of the bursa of Fabricius. These differences might be due to the age, breed and strain variations.

The lamina propria had loose connective tissue and lymphoid follicles in both Hansli chicken and Vencobb broiler chicken in all the age groups. The bursal follicles were irregular round, triangular, oval or elliptical in shape in both the birds. These lymphoid follicles were separated from each other by interfollicular connective tissue in both the birds. The bursal cysts were prominent and numerous in the lymphoid follicle of $4^{\text {th }}$ week age Vencobb broiler chicken. The follicular pattern were absent in the plicae and the connective tissue elements of lamina propria occupied most of the portions of the bursal plicae at $24^{\text {th }}$ week age in both the birds (Fig. 11). It indicated the 
process of regression of the organ at $24^{\text {th }}$ week of age in both Hansli chicken and Vencobb broiler chicken.

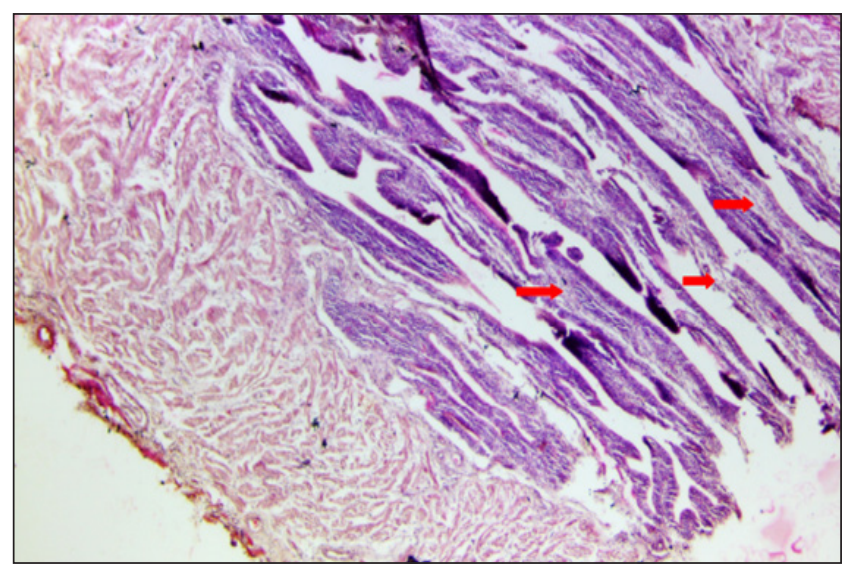

Fig. 11: Photograph showing the connective tissue elements of lamina propria (red arrows) occupying the bulk area inside the lymphoid follicles of bursa of Fabricius in Hansli chicken $\left(24^{\text {th }}\right.$ week) (H\&E x100)

The collagen, reticular and a few elastic fibers were reported in the interfollicular area, sub-epithelial connective tissue, centre of bursal plicae and blood vessels present in the interfollicular region of the organ in all the age groups in both the birds. The amount of the collagen fibers increased with the age in both the birds which imparted protection to the organ and played role in the replacement of cellular elements of the spleen. But the amount of elastic fiber gradually decreased with age in both the birds. Further, each bursal follicle consisted of peripheral cortex and central medulla and they were separated by a corticomedullary junction. The cortex of the follicle consisted of densely packed lymphocytes of various sizes, whereas the medulla had loosely arranged lymphocytes of various sizes. Both the regions had networks of reticular cells in both the birds in all the age groups. There was also presence of dendritic cells, erythrocytes and macrophages inside the lymphoid follicles in both Hansli chicken and Vencobb broiler chicken in all the age groups. The peripherally located lymphoid follicles were in direct contact with the surface epithelium of the bursa, whereas the rest of the bursal follicles were surrounded by the interfollicular connective tissue. The amount of reticular fibers increased in the bursa at $24^{\text {th }}$ week of age in both the Hansli chicken and Vencobb broiler chicken that might be attributable to the decreased number of lymphocytes and gradual replacement of the cellular elements which led to the involution of the bursa with age in both the birds.

There was presence of small, medium and large sized lymphocytes in both the cortex and medulla of the lymphoid follicle in both Hansli chicken and Vencobb broiler chicken. The reticuloepithelial cells were located in the cortex, medulla and connective tissue elements of the bursal follicles. They consisted of large vesicular nucleus with lightly stained cytoplasm (Fig. 12).

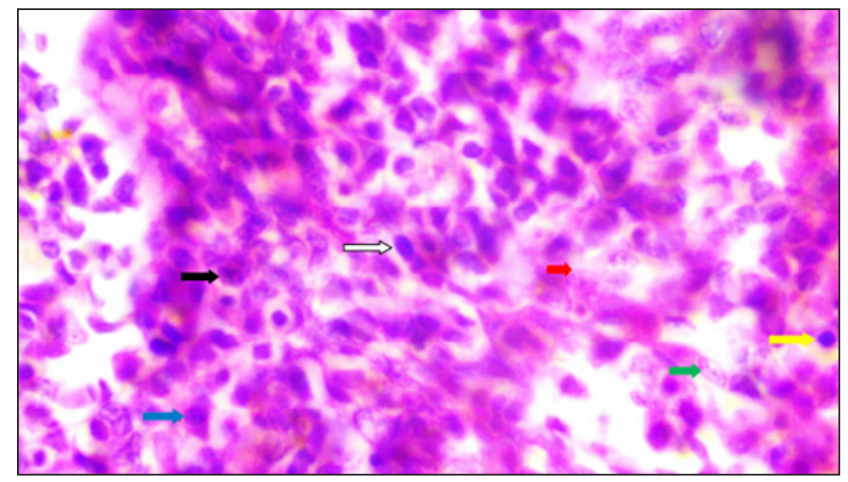

Fig. 12: Photograph showing the small (black arrow), medium (yellow arrow), large lymphocyte (white arrow), reticuloepithelial cells (red arrow), plasma cell (blue arrow) and dendritic cell (green arrow) in the lymphoid follicle of bursa of Fabricius in Hansli chicken (4th week) (H\&E x1000)

The macrophages had indented nucleus with vesiculated cytoplasm. The dendritic cells were elongated cells having long extended cytoplasmic processes. They had elongated vesicular nucleus. The cytoplasm of these cells was granular in appearance and light pink in colour. The plasma cells were reported in the cortex, medulla and interfollicular areas of the bursa having eccentric nucleus in both the birds. It was contradicting to the finding of Kumar et al. (2014) who observed few plasma cells in the cortex of the lymphoid follicle only in Khaki Campbell duck. The presence of these cells in the bursa might be attributed to their role in providing humoral immunity to both the birds. The fibroblasts were noted in the connective tissue elements of the organ. These cells were spindle shaped with centrally located round nucleus.

The tunica muscularis of the bursa of Fabricius had inner circular and outer longitudinal smooth muscle layer in Hansli chicken and Vencobb broiler chicken in all the age groups (Fig. 13). It was contradicting to the finding of 
Indu et al. (2005) who reported that the tunica muscularis of bursa had outer circular and inner longitudinal smooth muscle layers in White Pekin ducks. There was presence of blood vessels between the smooth muscle layers of tunica muscularis and at the base of each bursal plica.

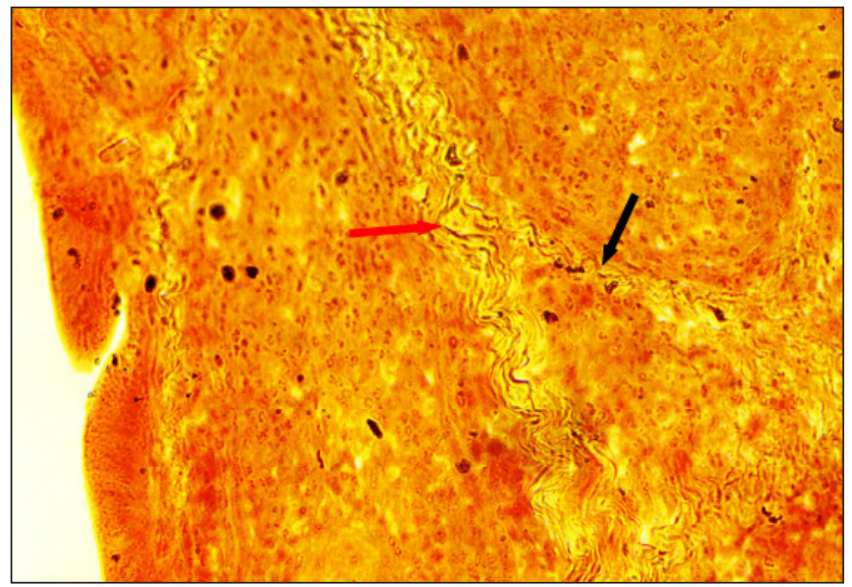

Fig. 13: Photograph showing elastic fiber in the central connective tissue core of plicae (red arrow) and between lymphoid follicles (black arrow) of bursa of Fabricius in Hansli chicken (12 ${ }^{\text {th }}$ week) (Gomori's method x100)

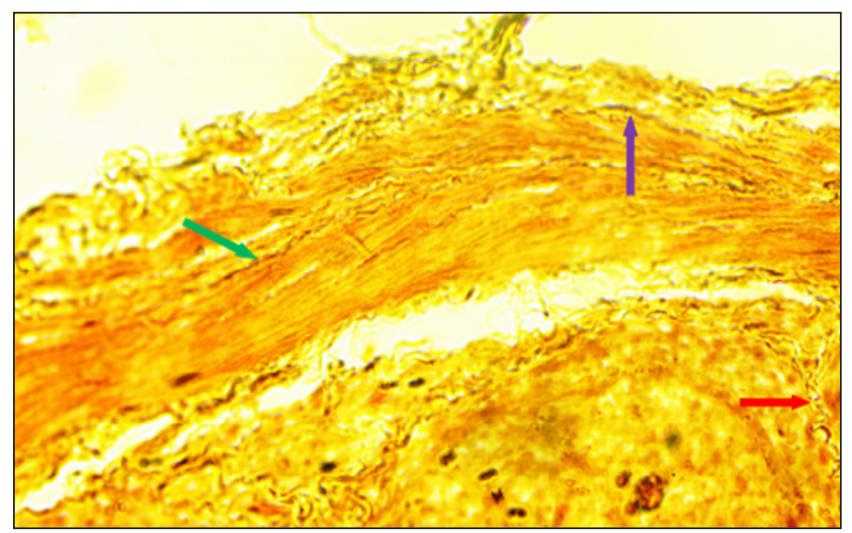

Fig. 14: Photograph showing elastic fiber in the central core of plicae (red arrow), tunica muscularis (green arrow) and tunica serosa (violet arrow) of Fabricius of Vencobb broiler chicken ( $4^{\text {th }}$ week) (Verhoeff's method $\mathrm{x} 400$ )

The tunica serosa was the outermost layer of the bursa in Hansli chicken and Vencobb broiler chicken in all the age groups. It had dense irregular type of connective tissue with fibroblasts, blood vessels and connective tissue fibers mostly collagen fibers as reported by Sari and Kurtdede (2007) in turkeys, Ingole et al. (2010) in CARI Shyama and
Vanaraja breeds of poultry, Singh et al. (2010) in chicken and Mahanta (2018) in local hill fowl of Uttarakhand and RIR. The collagen, reticular and elastic fibers (Fig. 14) were noted in the tunica muscularis, tunica serosa and walls of blood vessels located in both the tunica muscularis and serosa in Hansli chicken and Vencobb broiler chicken in all the age groups. The amount of collagen fibers increased with age in both the birds which imparted protection to the organ. But the elastic fibers gradually decreased with age that might be attributable to the decreased elasticity of the bursa with age in both Hansli chicken and Vencobb broiler chicken.

\section{CONCLUSION}

The present histological study provided a detailed baseline data on the age wise development of thymus, spleen and bursa of Fabricius in Hansli chicken and Vencobb broiler chicken which could be correlated with various molecular techniques in characterization of the age related immunogenic potency of these two breeds of poultry and basing on the outcome, they could be recommended to the farmers for rearing purpose.

\section{ACKNOWLEDGEMENTS}

The authors are grateful to the Dean, CVSc. and A.H., OUAT, Bhubaneswar for providing necessary facilities and support for the successful completion of this research work within time.

\section{REFERENCES}

Akter, S.H., Khan, M.Z.I., Jahan, M.R., Karim, M.R. and Islam, M.R. 2006. Histomorphological study of the lymphoid tissues of broiler chickens. Bang. J. Vet. Med., 4(2): 87-92.

Ali, M.M. 2015. Emerging prospective of emerging Indian livestock: A study on poultry sector. Asian J. Mgmt. Sci., 4(3): 33-39.

Ali, H.K. 2016. Anatomical and histological study of thymus gland in the local breed of Turkey (Meleagris gallopavo) in Iraq. $3^{\text {rd }}$ Scientific Conference, College of Veterinary Medicine, University of Tikrit, Iraq.

Bancroft, J.D. and Stevens, A. 1996. Theory and practice of histological techniques. $2^{\text {nd }}$ Edn., pp. 152-231, Edenbergh, London, Mlourna and New York.

Dahariya, N., Sathapathy, S., Mishra, U.K., Patra, R., Dehury, S., Joshi, S.K., Sahu, S.K. and Samal, L. 2020a. Gross 
morphological and biometrical studies on the spleen in various chicken genotypes. J. Ent. Zool. Stud., 8(5): 623-625.

Dahariya, N., Sathapathy, S., Mishra, U.K., Patra, R., Joshi, S.K., Sahu, S.K., Samal, L. And Biswadeep Jena 2020b. Gross morphological and biometrical studies on the bursa of fabricius in various chicken genotypes. J. Ent. Zool. Stud., 8(5): 626-628.

Ekka, R., Behura, N.C., Samal, L., Nayak, G.D., Pati, P.K., Mishra, P.K. 2016. Growth performance and linear body measurements of Hansli, CSML and Hansli $\times$ CSML cross under intensive system of rearing. J. Livest. Sci, 7:114-121.

Gulmez, N. and Aslan, S. 1999. Histological and histochemical investigations on bursa of Fabricius and thymus of native geese. Turk. J. Vet. Anim. Sci., 23: 163 - 171.

Hassan, S.A., AI-Tememy, Hussien, J.S. and Rasool, B.S. 2011. Histological study of bursa of Fabricius of Quail birds (Coturnix coturnix japonica). Egypt. J. Poult. Sci., 31(2): 613-620.

Indu, V.R., Chungath, J.J., Harshan, K.R. and Ashok, N. 2005. Morphology and histochemistry of the bursa of Fabricius in White Pekin ducks. Ind. J. Anim. Sci., 75(6): 637 - 639.

Ingole, S.P., Jain, P. and Dang, U. 2010. Gross and histological studies on bursa of Fabricius of CARI Shyama and Vanaraja breeds of poultry. Haryana Vet., 49: 51- 53.

Jayachitra, S., Balasundaram, K., Kumaravel, A. and Jagapathi Ramayya, P. 2009. Gross anatomical studies on the bursa of Fabricius of turkey (Meleagris gallopavo). Ind. J. Vet. Anat., 21(1): 33-36.

Kannan, T.A. and Geetha, R. 2013. Light and electron microscopic details of blood-spleen barrier in Nandanam chicken (Gallus domesticus). Int. J. Sci. Res., 4(6): 22032206.

Kannan, T.A., Geetha, R., Ushakumari, S., Dhinakarraj, G. and Vairamuthu, S. 2015. Light microscopic studies on Spleen of Chicken (Gallus domesticus). Haryana Vet., 51(12): 114-5.

Khan, M.Z.I., Masum, M., Zubayer, M., Khan, I., Aziz, A.R.B., Nasrin, M., Siddique, M.N.H. and Arshad, M.M. 2014. Histomorphology of the lymphoid tissues of broiler chicken in Kelantan, Malaysia. Sains Malaysiana., 43(8): 1175-1179.

Kumar, S., Kumar, A., Singh, B., Sharma, R.K., Singh, D. and Singh, S.K. 2014. Study on blood biochemical parameters and carcass trait in Uttara Fowl. Ind. Vet. J., 91(9): 107-108.
Lochi, G.M., Haseeb, A., Shah, M.G., Gandahi, J.A., Khan, M.S., Faisal, M., Kiani, F.A., Mangi, R.A. and Oad, S.K. 2014. Histo-morphological study on thymus of aseel chicken. J. Agri. Food Tech., 4(2): 1-5.

Mahanta, D. 2018. Comparative study on the major lymphoid organs of local hill fowl of Uttarakhand and Rhode Island Red. M.V.Sc. Thesis submitted to G.B. Pant Univ. Agri. \& Tech., Pantnagar.

Mohapatra, S.C., Mishra, S.C. and Das, K. 2016. Poultry Genetic Resources of Orissa (ISNNRMPO Programme Series 4), pp. 1-58, Published by Intercorporation India-Deligation, Hyderabad and Indo-Swiss Natural Resources Management Programme, Orissa, Bhubaneswar.

Padhi, M.K. 2016. Importance of indigenous breeds of chicken for rural economy and their improvements for higher production performance. Scientifica, pp. 9 .

Sari EK and Kurtdede N. 2007. Light and electron microscopic studies of the bursa of Fabricius in turkeys. Kafkas Universitesi Veteriner Fakultesi Dergisi., 13(2): 177-184.

Senapati, M.R., Behera, P.C., Maity, A. and Mandal, A.K. 2015. Comparative histomorphological study on the thymus with reference to its immunological importance in Quail, Chicken and Duck. Explo. Anim. Med. Res., 5(1):73-77.

Singh, G.K., Chauhan, R.S. and Mishra, U.K. 2010. Histomorphological development of lymphoid organs in chicken: thymus and bursa of Fabricius. J. Immun. Immunopatho., 12(1): 20-28.

Snedecor, G.W. and Cochran, W.G. 1994. In "Statistical methods" $8^{\text {th }}$ Edn., Oxford and IBH Publishing House, Calcutta, India.

Song hui, Peng Kemei, Shenghe Li, Yan Wang, Lan Wei and Li Tang. 2012. Morphological characterization of the immune organs in ostrich chicks. Turk. J. Vet. Anim. Sci., 36(2): 89100 .

Sultana, N., Khan, M.Z.I., Wares, M.A. and Masum, M.A. 2011. Histomorphological study of the major lymphoid tissues in indigenous ducklings of Bangladesh. Bang. J. Vet. Med., 9(1): 53-58.

Venkatesan, S. and Vijayaragavan. 1999. Microanatomical studies on the spleen of Japanese quail. Ind. J. Vet. Anat., 11(1): 61 . 
